\title{
Tranexamic Acid: Implementing a Clinical Guideline for its use in a Moderate Resource Setting
}

\author{
Article by Hemchand Jhagru \\ Department of Pre-Clinical Sciences, College of Medicine, Texila American University, \\ Guyana, South America
}

\begin{abstract}
Background: Guyana, located on the northern South American Mainland is a moderate resource, developing country with high rates of traumatic hemorrhage. There is a shortage of blood products available for use in the emergency department of Georgetown Public Hospital, the main tertiary public hospital. Tranexamic acid (TXA) is an antifibrinolytic that inhibits both plasminogen activation and plasmin activity, thus preventing clot breakdown. CRASH-2, a large randomized, multicenter double blind, placebo-controlled clinical trial, that showed that TXA reduces mortality and blood product use in acute trauma in a moderate resource setting. Currently TXA is not available for use in the public health system in Guyana.

Methods: A literature review was conducted using Google Scholar and PubMed, and by analyzing review articles from the Cochrane Database, European Guidelines, NICE Guidelines. Sources were analyzed to determine pharmacology, feasibility and utility of TXA in moderate resource emergency medicine settings such as Guyana. Steps were taken to bring TXA for use in the public health system in Guyana.

Results: Meetings with stakeholders. Cost analysis. A protocol for initial utilization. Plan for data collection and future expansion.

Conclusions: Tranexamic acid is a safe and inexpensive drug that should be incorporated into trauma clinical guidelines for the resuscitation of the bleeding patient at Georgetown Public Hospital. Implementing a clinical guideline for the use of tranexamic acid in trauma at GPHC will improve mortality due to bleeding and reduce the use of blood products.
\end{abstract}

Keywords: Tranexamic acid; Acute trauma; Moderate resource setting.

\section{Introduction}

Guyana is a low middle-income developing country located on the northern mainland of South America. It has cultural, historical and political ties with the Caribbean Community. Guyana is bordered by the Atlantic Ocean to the north, Brazil to the south-west, Suriname to the east and Venezuela to the west $t^{1}$. Guyana has an area of $215,000 \mathrm{~km}^{2}$ with approximately 750,000 inhabitants ${ }^{2}$.

Georgetown, the capital city, has the only public tertiary health care facility in the country, Georgetown Public Hospital Cooperation (GPHC). Georgetown Public Hospital Corporation is the main referral center in Guyana. According to data obtained from the records department of GPHC, the Accident \& Emergency department treats approximately 3800 patients per month of which motor vehicle accidents account for approximately $4.5 \%$ of visits and assaults $6.3 \%$ of visits.

\section{Epidemiology and pathophysiology of traumatic hemorrhage}

Injuries from trauma result in the death of more than five million people worldwide every year ${ }^{3}$. Uncontrolled post-traumatic bleeding is the leading cause of potentially preventable death, accounting for up to $30 \%$ of the mortality among these patients ${ }^{4,5}$. Major surgery and trauma have similar effects on the hemostatic pathway. Physiologic pathways of clot breakdown (fibrinolysis) can progress to hyperfibrinolysis- which significantly increases mortality $(70-100 \%)^{6}$.

Antifibrinolytic agents such as tranexamic acid is proven to reduce blood loss in patients with both normal and exaggerated fibrinolytic responses in surgery, without increasing the risk of postoperative complications ${ }^{7}$. About $25 \%$ patients with severe traumatic injury will have an abnormality in the coagulation system. This entity, called acute coagulopathy of trauma, is associated with 
increased morbidity, mortality and need for transfusion ${ }^{8}$. Blood is a scarce and expensive resource in low income countries. Furthermore, the risk of transfusion-related infections is more prevalent in low resource, developing countries ${ }^{9}$.

\section{Acute coagulopathy of trauma}

The presence of coagulopathy in trauma is a reflection of the severity of injury and correlates with mortality ${ }^{10}$. Trauma-induced coagulopathy is different from disseminated intravascular coagulation (DIC). DIC is characterized by generalized intravascular micro coagulation with subsequent factor consumption whereas in acute traumatic coagulopathy, there is a bleeding-related loss of coagulation factors and platelets ${ }^{11}$.

Coagulopathy in trauma is caused by a loss of clotting factors and platelets by bleeding, and dilutional coagulopathy after administration of fluids to maintain blood pressure ${ }^{12}$. Also, activation of the fibrinolytic system and subsequently hyperfibrinolysis, hypothermia, acidosis, and hypoperfusion (due to hypotension and shock) directly affect fibrinogen polymerization and coagulopathy ${ }^{13,14}$. The prevention of shock and acidosis due to hypovolemia and hypoperfusion are important to prevent coagulopathy. Acidosis causes impaired enzyme activity, depleted fibrinogen levels and platelet counts, prolonged clotting time, and increased bleeding time ${ }^{15}$. Hypoperfusion leads to decreased oxygen delivery, increased lactate production, and metabolic acidosis ${ }^{16}$. Decreased endogenous heat production exacerbates hypothermia caused by environmental exposure and injudicious administration of cold resuscitation fluids and blood. This causes clinically significant reduction in platelet function and aggregation ${ }^{17}$. Below $34^{0} \mathrm{C}$, each drop-in temperature by $1^{\circ} \mathrm{C}$ is associated with a $10 \%$ drop in platelet function ${ }^{18}$

\section{Pathogenesis of hyperfibrinolysis}

Fibrinolysis occurs through the proteolytic effects of plasmin, which is activated from plasminogen by tissue plasminogen activator (t-PA). Once formed, plasmin cleaves fibrin into small protein fragments. Negative control of the fibrinolytic system comes from direct inhibition of plasmin by plasminogen activator inhibitor 1 (PAI-1) and thrombin activatable fibrinolysis inhibitor (TAFI), which block the conversion of plasminogen to plasmin, thus inhibiting fibrinolysis ${ }^{19}$. The activation of protein $\mathrm{C}$ results in a proteolytic deactivation of clotting factors Va and VIIIa and enhanced fibrinolysis through a decrease in PAI-1(normally inhibits t-PA), which results in an increase in t-PA activity and increased fibrinolysis ${ }^{20}$.

\section{Methodology}

Using online databases Google Scholar and PubMed, a primary literature search was done for articles published between January 2004 - August 2016 with key words 'tranexamic acid', 'trauma', 'pharmacology', 'history', 'CRASH 2 trial and analysis', 'MATTERS trial'. Review articles from Cochrane database, European Guidelines, and NICE Guidelines were obtained. Pertinent information on pharmacology of TXA and clinical application of TXA in trauma was abstracted.

\section{Pharmacology of tranexamic acid}

Tranexamic acid is an antifibrinolytic that inhibits both plasminogen activation and plasmin activity, thus preventing clot break-down rather than promoting new clot formation ${ }^{21}$. The process of fibrin breakdown begins when plasminogen, a glycoprotein pro-enzyme produced by the liver, binds to strands of fibrin. The plasminogen molecule is folded into loops called kringles. Plasminogen binds to fibrin via lysine binding sites at the ends of these loops. Tranexamic acid acts by occupying the lysine-binding sites on plasminogen, thereby blocking the binding site of lysine residues on fibrin. This reduces plasminogen activation to plasmin. Similarly, blockade of lysine-binding sites on circulating plasmin prevents binding to fibrin and thus prevents clot break- down ${ }^{22}$.

Tranexamic acid does not affect platelet count or aggregation or coagulation parameters. It is excreted largely unchanged in urine and has a half-life of about 2 hours in circulation. Dosing should be adjusted for renal impairment, but no adjustment is needed for hepatic impairment ${ }^{23}$. TXA crosses the placenta but is safe during pregnancy. (24) Tranexamic acid is supplied in ampules of $1000 \mathrm{mg}$ in $10 \mathrm{ml}$ water for injection. It is stored at room temperature ${ }^{25}$. 


\section{Applications of tranexamic acid}

In the 1970s to 1990s, tranexamic acid was used to control bleeding in a number of clinical settings including dental extraction in patients with hemophilia, menstrual bleeding, in pediatric urinary tract surgery, ruptured intracranial aneurysms, oral and dental surgery, gynecologic surgery, treatment of hereditary angioneurotic edema, upper gastrointestinal hemorrhage and traumatic hyphema ${ }^{26}$. Tranexamic acid has been proven to reduce blood loss and need for transfusion in cardiopulmonary bypass, liver transplantation and hip or knee arthroplasty ${ }^{27,28}$.

A systematic review by Henry et al in 2011, showed that tranexamic acid reduced the need for transfusions in elective surgery by $30 \%$ and the need for further surgery to control bleeding by $50 \%{ }^{29}$. Concerns regarding risk of thrombosis with use of tranexamic acid have not been substantiated in clinical trials ${ }^{30}$.

\section{Tranexamic acid in traumatic hemorrhage: the CRASH-2 trial}

The Clinical Randomization of an Antifibrinolytic in Significant Hemorrhage 2 (CRASH-2) Trial was a large international randomized, double blinded, multicenter placebo-controlled clinical trial of the effects of the early administration of tranexamic acid on death, vascular occlusive events, and blood transfusion in trauma patients with significant hemorrhage. This study was undertaken in 274 hospitals in 40 countries and enrolled 20,211 patients with, or at risk of, significant bleeding. The patients were randomly assigned to either tranexamic acid (loading dose $1 \mathrm{~g}$ over $10 \mathrm{~min}$ followed by infusion of $1 \mathrm{~g}$ over $8 \mathrm{~h}$ ) or placebo ${ }^{31}$. This study was published in the Lancet in 2010.

The inclusion criteria were as follows:

1. Adult trauma patients with or at risk of significant haemorrhage

2. Systolic blood pressure (SBP) less than $90 \mathrm{~mm} \mathrm{Hg}$

3. Heart rate of more than 110 beats per minute

4. Presentation within 8 hours of injury

\section{Benefits of TXA in CRASH-2}

The Primary Outcome measured all-cause 28-day mortality and was 1,463 (14.5\%) in the tranexamic acid group and 1,613 (16.0\%) in placebo patients (absolute risk reduction 1.5\%, RR 0.91, NNT 67, $\mathrm{p}=0.0035)^{31}$. This $1.5 \%$ absolute risk reduction means that one would have to treat 67 trauma patients with TXA to prevent one from dying of any cause (number needed to treat $=1 /$ absolute risk reduction) ${ }^{26}$. The authors also reported a reduction of death as a result of bleeding of $15 \%$ ( RR $0.85, \mathrm{p}$ 0.0077) ${ }^{32}$. Secondary outcomes measured vascular occlusive events (myocardial infarction, stroke, pulmonary embolism [PE] and deep vein thrombosis [DVT], receipt of blood transfusion, and units of blood products transfused. No significant difference in blood transfusions (about $50 \%$ in both groups) or thrombo-embolic events (1.7\% in TXA, $2.0 \%$ in placebo group) were found ${ }^{31}$.

An exploratory analysis of the effect of tranexamic acid on mortality due to bleeding according to time to treatment, severity of hemorrhage (assessed by systolic blood pressure, Glasgow coma score) and type of injury were assessed ${ }^{32}$. It was published in the Lancet in 2011 by CRASH-2 collaborators. This assessment indicated that the effect of TXA varied by time to treatment. Treatment within one hour of injury was associated with a $32 \%$ relative reduction in risk of death due to bleeding (RR 0.68 , $\mathrm{P}<0.0001)$ and treatment between one and three hours after injury was associated with a $21 \%$ reduction $(\mathrm{RR} 0.79, \mathrm{P}=0.03)$. Treatment with TXA after three hours of injury was associated with a $44 \%$ relative increase in risk of death due to bleeding when compared to the placebo group. (RR 1.44, $\mathrm{P}=0.004)^{32}$. Patients receiving tranexamic acid within 3 hours received less blood transfusion than those in the control group (mean difference $-0.21, \mathrm{P}=0.04)^{33}$. There was no statistically significant difference in risk for stroke, pulmonary embolism, deep vein thrombosis and surgical intervention between the groups. The authors of CRASH-2 concluded that tranexamic acid should be given as early as possible to bleeding trauma patients ${ }^{32}$. For trauma patients given TXA more than 3 hours after injury, tranexamic acid is less effective at controlling bleeding and could be harmful ${ }^{33}$.

\section{Matters study}

The MATTERs study is a retrospective observational study comparing tranexamic acid to no 
tranexamic acid in combat casualty patients. Results showed that the TXA group had lower mortality than the group not given TXA (17.4\% vs. $23.9 \%)$. This benefit was greatest in polytrauma patients $(14.4 \%$ vs. $28.1 \%)$ where tranexamic acid was also independently associated with survival and less coagulopathy $(\mathrm{p}=0.003)^{34}$.

\section{Quality of evidence}

CRASH-2 was done in different healthcare settings around the world and involved a large and diverse study population. Most of the 274 study sites in CRASH-2 were in low-income and middleincome countries, where other treatments directed at coagulopathy, such as fresh frozen plasma, platelets, and cryoprecipitate, are not as readily available. This shows that the results are generalizable across settings. The CRASH-2 was a clinical, randomized, double-blinded, placebo- controlled trial with intention-to-treat analysis. The FDA considers this type of study to be the highest level of evidence in clinical studies ${ }^{26}$. The intention to treat approach of CRASH-2 demonstrated that the drug effect is still observed in real world settings even if the drug was subsequently changed or discontinued in a proportion of patients. Also, over $99 \%$ of patients were followed up so there was minimal bias due to attrition ${ }^{33}$.

\section{Cost effectiveness}

A quotation of the cost of TXA was requested from International Pharmaceutical Agency (IPA), which is one of the main retailing pharmaceutical companies in Guyana. They submitted an invoice which estimated that an ampule of tranexamic acid would cost \$300 Guyana dollars. This would amount to \$ 3 USD per patient.

\section{Ongoing studies}

There are a number of ongoing studies evaluating the possible use of TXA in gastrointestinal bleed (HALT-IT), postpartum hemorrhage (WOMAN) and traumatic brain injury (CRASH-3) ${ }^{36}$. Tranexamic acid has been adapted into the treatment protocol of Emergency Medical Services (EMS) in countries such as Australia where the acutely injured patient may be more than 3 hours away from a health facility capable of providing trauma care ${ }^{37,38}$. This is important since the greatest effect on mortality is within the first hour of traumatic bleeding ${ }^{32}$.

\section{WHO list of essential drugs}

The world health Organization (WHO) reviewed the evidence for the use of TXA from CRASH-2 and related studies, and listed TXA on the List of Essential Drugs due to its mortality reduction in traumatic hemorrhage ${ }^{39}$.

\section{Development of ED Clinical Practice Guideline for TXA at GPHC}

Based on the enrollment procedures, inclusion and exclusion criteria of CRASH-2, a simplified clinical practice guideline was developed to indicate which patients with significant hemorrhage should receive TXA at GPHC. The guideline was designed to advise clinicians treating acutely injured patients with bleeding (Figure 1). Significant hemorrhage was defined as the attending physician's clinical gestalt that there is a likelihood that patient would need a blood transfusion and would therefore need to be grouped and crossed match.

\section{Implementation of TXA at GPHC}

Tranexamic acid as an adjunct in the treatment of the bleeding trauma patient was proposed to the Director of Residency of emergency medicine, Dr N. Forget and to the Head of Department of emergency medicine at GPHC, Dr Z. Bux in April 2016.

A comprehensive review of the literature on tranexamic acid was done over the following months and a clinical guideline for the use of TXA in acute trauma was formulated. (figure 1). This clinical guideline was presented to Dr Forget and Dr Bux in October 2016 and meetings were scheduled with various stakeholders such as the Pharmacy Committee, the Blood Bank and the Management Committee of GPHC.

A presentation of the clinical guideline to the Department of General Surgery and Orthopedics, 
who are responsible for definitive management of severe traumatic injury at GPHC was done in November 2016. And during the months of January and February 2017, the Management Committee of GPHC, the Director of the Blood Bank and the representatives of the Pharmacy Committee were presented to the benefits and lifesaving attributes of TXA.

The clinical guideline formulated for the use of TXA in acute trauma was approved and endorsed by the hospital leadership other stakeholders aforementioned. Thus, the process of adding tranexamic acid to the national formulary of medications started and is ongoing. The Pharmacy Committee is currently in the process of purchasing the medication so that it can be stocked for use in the emergency department.

Many of the physicians in the emergency department of GPHC are not familiar with the use of tranexamic acid in trauma. Ongoing provider education and supervision where the shift supervisor of the emergency department ensures that the clinical guideline is adhered to and that presenting trauma patients who meet the inclusion criteria are given the medication appropriately.

Nurses will be taught the pharmacokinetics of tranexamic acid and how to administer it according to the clinical guidelines in the following months.

A donation of 10 vials of TXA from a NGO (Non-Government Organization) was given to the emergency department and TXA has already been administered to two patients with favourable outcomes.

Continuous monitoring and assessment of the use of TXA in the emergency department is an ongoing task. The trauma registry is in the process of implementation and installation. The use of TXA will be one of the parameters that will be monitored by the trauma registry as well as primary outcome (mortality) and the use of blood products. In the meantime, monitoring and assessment is done by completion of a data collection sheet (see annex) by the shift supervisor and the patient's primary outcome (mortality) and secondary outcome (use of blood products) are monitored with visits to the admitting ward.

\section{Plans for TXA in the Near Future at GPHC}

The Obstetrics and Gynecology department of GPHC has asked about the process of implementing a guideline for the management of postpartum hemorrhage and as a drug given before cesarean section to minimize bleeding. Tranexamic acid would be very useful in our setting when used as an adjunct for GI bleeds as these patients face the same constraint as in trauma, with inadequate supply of necessary blood products. There is also scope for its use in ENT and in orthopedics for joint replacement surgeries which are often complicated by bleeding and then secondarily infection.

In Guyana, there are numerous regional hospitals and health posts in the forested and hinterland regions where access to tertiary and definitive health can often be delayed. The use of TXA by doctors and nurses in these hospitals would decrease bleeding and improve mortality and morbidity. TXA can also be used in pre-hospital settings by EMS when evacuating patients. The clinical guideline can be followed by online medical direction. These are the areas that tranexamic acid will expand to in the coming months and years as it's use become more popular and the relevant departments and services are educated to its safety and usefulness.

\section{Conclusions}

TXA is an important antifibrinolytic agent with demonstrated ability to cost-effectively improve mortality and reduce need for blood products in the acutely bleeding trauma patient. The clinical practice guideline proposed here shows that use of TXA in the GPHC emergency department is a feasible and practical way to save lives in trauma management. There is also great scope for the incorporation of TXA into clinical guidelines in other areas of medicine where acute bleeding is a problem and for EMS and Regional Hospitals to use tranexamic acid in acute hemorrhage. 
DOI: 10.21522/TIJBMS.2016.04.01.Art004

ISSN: $2519-500 \mathrm{X}$

Figure 1

CLINICAL GUIDELINE FOR THE USE OF TRANEXAMIC ACID

IN THE EMERGENCY DEPARTMENT OF GPHC

Inclusion Criteria

1. Age $>16$ yrs

2. Systolic $\mathrm{BP}<90 \mathrm{mmHg}$

3. Pulse $>110$

4. Bleeding or at risk of ' significant' hemorrhage

Presents within $3 \mathrm{hrs}$ of injury

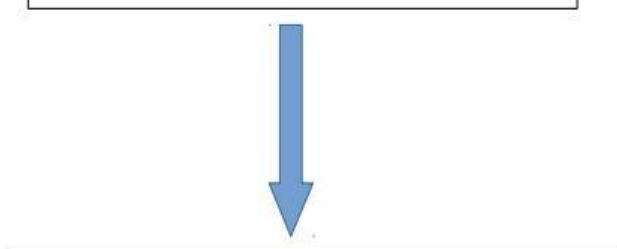

Exclusion Criteria

1. Known allergy

YES DO NOT

2. Active tromboembolic event (stroke, DVT,PE, DIC) ADMINISTER

NO

Administer Tranexamic acid $1 \mathrm{~g}$ in $100 \mathrm{mls}$ of N/S over $10 \mathrm{~min}$ then

Tranexamic acid $1 \mathrm{~g}$ in $1000 \mathrm{mls}$ of N/S over $8 \mathrm{hrs}$ 


\section{Annex}

\section{Data Collection form for the use of Tranexamic ACID}

\begin{tabular}{|l|l|l|l|l|l|l|l|l|}
\hline Name of Patient & $\begin{array}{l}\text { Date } \\
\text { Seen }\end{array}$ & Diagnosis & \multicolumn{2}{|l|}{ Vital Signs } & Disposition & $\begin{array}{l}\text { Primary outcome } \\
\text { (mortality) }\end{array}$ & $\begin{array}{l}\text { Secondary outcome } \\
\text { (blood products given) }\end{array}$ \\
\cline { 4 - 8 } & & & BP & Pulse & & & In ER & In ward \\
\hline & & & & & & & & \\
\hline & & & & & & & & \\
\hline & & & & & & & & \\
\hline & & & & & & & & \\
\hline & & & & & & & & \\
\hline
\end{tabular}

\section{References}

[1]. Health in the Americas, 2012 Edition: Country Volume N' Pan American Health Organization, 2012. Available from: http://www.paho.org/saludenlasamericas/index.php?option=com_docman\&task=doc_view\&gi $\mathrm{d}=133 \&$ Itemid $=$

[2]. Guyana, Bureau of Statistics. Population \& Housing Census 2012. Available from: http://www.statisticsguyana.gov. gy/census.html

[3]. Murray CJ, Lopez AD: Alternative projections of mortality and disability by cause 1990-2020: Global Burden of Disease Study. Lancet 1997, 349:1498-1504.

[4]. Kauvar DS, Lefering R, Wade CE. Impact of hemorrhage on trauma outcome: an overview of epidemiology, clinical presentations, and therapeutic considerations. J Trauma. 2006;60: S3-S11.

[5]. World Health Organisation: World Health Statistics 2009: Cause-specific mortality and morbidity. [http://www.who.int/whosis/whostat/ EN_WHS09_Table2.pdf].

[6]. Kashuk JL, Moore EE, Sawyer M, Wohlauer M, Pezold M, Barnett C, Biffl WL, Burlew CC, Johnson JL, Sauaia A. Primary fibrinolysis is integral in the pathogenesis of the acute coagulopathy of trauma. Ann Surg. 2010; 252:434Y442; discussion 443Y444.

[7]. Lawson JH, Murphy MP. Challenges for providing effective hemostasis in surgery and trauma. Seminars in Hematology 2004;41(1 Suppl 1):55-64.

[8]. Brohi K, Singh J, Heron M, Coats T. Acute traumatic coagulopathy. J Trauma. 2003; 54:1127- 1130.

[9]. Sihler KC, Napolitano LM: Complications of massive transfusion. Chest 137:209-220, 2010.

[10]. MacLeod JB, Lynn M, McKenney MG, Cohn SM, Murtha M. Early coagulopathy predicts mortality in trauma. J Trauma 2003; 55: 39-44.

[11]. Fries D, Streif W, Haas T, Kuhbacher G. Dilutional coagulopathy, an underestimated problem? Anasthesiol Intensivmed Notfallmed Schmerzther 2004; 39: 745-50.

[12]. Gruen RL, Brohi K, Schreiber M, et al. Haemorrhage control in severely injured patients. Lancet. 2012; 380:1099-1108.

[13]. Hess John R, Brohi Karim, Dutton Richard P, et al. The coagulopathy of trauma: a review of mechanisms. J Trauma. 2008; 65:748e754.

[14]. Brohi K, Cohen MJ, Ganter MT, et al. Acute coagulopathy of trauma: hypoperfusion induces systemic anticoagulation and hyperfibrinolysis. J Trauma 2008; 64: 1211-17.

[15]. Lynn M, Jeroukhimov I, Klein Y, Martinowitz U. Updates in the management of severe coagulopathy in trauma patients. Intensive Care Med 2002; 28(Suppl. 2): S241-7.

[16]. Jansen JO, Scarpelini S, Pinto R, Tien HC, Callum J. Hypoperfusion in severely injured patients is associated with reduced coagulation factor activity. J Trauma. 2011 Nov;71(5 suppl 1): S435eS440.

[17]. Wolberg AS, Meng ZH, Monroe 3rd DM, Hoffman M. A systematic evaluation of the effect of temperature on coagulation enzyme activity and platelet function. J Trauma. 2004 June;56(6):1221e1228.

[18]. Tsuei BJ, Kearney PA. Hypothermia in the trauma patient. Injury. 2004 Jan;35(1):7e15. 
[19]. Medcalf RL. Fibrinolysis, inflammation, and regulation of the plasminogen activating system. J Thromb Haemost. 2007;5(Suppl 1):132Y142.

[20]. Davidson CJ, Tuddenham EG, McVey JH. 450 million years of hemostasis. J Thromb Haemost. 2003; 1:1487Y1494.

[21]. McCormack PL. Tranexamic acid: a review of its use in the treatment of hyperfibrinolysis. Drugs. 2012; 72:585Y617.

[22]. Lucas M, Fretto L, McKee P. The binding of human plasminogen to fibrin and fibrinogen. J Biol Chem 1983; 258: 4249-56.

[23]. http://www.drugbank.ca/drugs/DB00302.

[24]. http://www.ncbi.nlm.nih.gov/pubmed/3321402.

[25]. Pfizer. Cyklokapron (tranexamic acid) injection package insert. 2008. Available at: www.pfizer.com/products/rx/prescription.jsp. In.

[26]. Andrew P. Cap, MD, PhD, David G. Baer, PhD, Jean A. Orman, MPH, ScD, James Aden, PhD, Kathy Ryan, PhD, and Lorne H. Blackbourne, MD. Tranexamic Acid for Trauma Patients: A Critical Review of the Literature. DOI 101097TA0b013e31822114af.

[27]. Karski JM, Teasdale SJ, Norman P, et al. Prevention of bleeding after cardiopulmonary bypass with highdose tranexamic acid. Double-blind, randomized clinical trial. J Thorac Cardiovasc Surg. 1995; 110:835-842.

[28]. Eubanks JD. Antifibrinolytics in major orthopaedic surgery. J Am Acad Orthop Surg. 2010; 18:132-138.

[29]. Henry DA, Moxey AJ, Carless PA, O'Connell D, Henderson KM, Fergusson D, et al. Anti- fibrinolytic use for minimising perioperative allogeneic blood transfusion. Cochrane Database of Systematic Reviews 2011, Issue 1. [DOI: 10.1002/14651858.CD001886.pub2].

[30]. Colman R, ed. Hemostasis and Thrombosis Basic Principles and Clinical Practice. 5th ed. Philadelphia, PA: Lippincott Williams \& Wilkins; 2006.

[31]. CRASH-2 trial collaborators, Shakur H, Roberts I, Bautista R, Caballero J, Coats T, Dewan Y, El-Sayed $\mathrm{H}$, Gogichaishvili T, Gupta S, et al. Effects of tranexamic acid on death, vascular occlusive events, and blood transfusion in trauma patients with significant haemorrhage (CRASH-2): a randomised, placebo-controlled trial. Lancet. 2010; 376:23.

[32]. CRASH-2 collaborators, Roberts I, Shakur H, Afolabi A, Brohi K, Coats T, et al. The importance of early treatment with tranexamic acid in bleeding trauma patients: an exploratory analysis of the CRASH-2 randomised controlled trial. Lancet 2011;377(9771):1096-101.

[33]. Ker K, Roberts I, Shakur H, Coats TJ. Antifibrinolytic drugs for acute traumatic injury. Cochrane Database of Systematic Reviews 2015, Issue 5. Art. No.: CD004896. DOI:

[34]. 10.1002/14651858.CD004896.pub4.

[35]. Morrison JJ, Dubose JJ, Rasmussen TE, Midwinter MJ. Military Application of Tranexamic Acid in Trauma Emergency Resuscitation (MATTERs) Study. Arch Surg. 2012; 147:113Y119.

[36]. Guerriero C, Cairns J, Perel P, Shakur H, Roberts I: Cost-effectiveness analysis of administering tranexamic acid to bleeding trauma patients using evidence from the CRASH-2 trial. PLoS One 2011, 6: e18987.

[37]. http://epmonthly.com/article/its-time-to-embrace-txa-for-traumatic-bleeds/.

[38]. Erik Nelson Vu, CCP, MD, FRCPC, DAvMed,1,2,3 Rob S. Schlamp, CCP,1 Robert T. Wand, CCP,1 Geoff A. Kleine-Deters, CCP, RN,1. Prehospital Use of Tranexamic Acid for Hemorrhagic Shock in Primary and Secondary Air Medical Evacuation. 1067-991X3600 Copyr 2013 Air Med J Assoc Httpdxdoiorg101016jamj201305001.

[39]. Brown JB, Neal MD, Guyette FX, Peitzman AB, Billiar TR, Zuckerbraun BS, et al. Design of the Study of Tranexamic Acid during Air Medical Prehospital Transport (STAAMP) Trial: Addressing the Knowledge Gaps. Prehosp Emerg Care. 2015 Jan 2;19(1):79-86.

[40]. Summary of the report of the 18th meeting of the WHO Expert Committee on the Selection and Use of Essential Medicines, 18th Meeting, Accra, Ghana March 21Y25, 2011. Available a Accessed November 10, 2012. 